\title{
Testing for haptic perception
}

\author{
Avaliação da percepção háptica \\ Laura Silveira-Moriyama1', Geruza Perlato Bella²
}

\author{
${ }^{1}$ Universidade Nove de Julho, \\ Postgraduate Program in Medicine, \\ São Paulo, Brazil. \\ 2Universidade Estadual de \\ Campinas, Faculdade de Ciências \\ Médicas, Departamento de \\ Neurologia, Campinas SP, Brazil. \\ Correspondence: \\ Laura Silveira-Moriyama; Programa \\ de Pós-graduação em Medicina, \\ Universidade Nove de Julho; Rua \\ Vergueiro, 235/249;01504-001 São \\ Paulo SP, Brasil. \\ E-mail:laurasm@uninove.br \\ Conflict of interest: \\ There is no conflict of interest to \\ declare. \\ Received 18 December 2015 \\ Accepted 21 December 2015

\section{(cc) BY}

$\mathrm{I}$ $\mathrm{n}$ this edition of Arquivos de Neuropsiquiatria Nascimento et al. ${ }^{1}$ present the results of a group effort in the development of a scale to measure haptic perception. Haptic perception is the "extraction of information about an object's properties such as its size, shape, and texture by means of exploratory manual movements"'. Although haptic perception is largely dependent on touch, it is intrinsically linked to proprioception and to motor skills, and it sits at the borderland between the sensory and the motor system integration. In addition, haptic sensing requires integration of information across time, because as the subject manipulates the object, the sensory information changes and needs to be re-integrated ${ }^{3}$.

Classic and widely practiced neurological examination usually includes subjective testing of the sensory modalities in isolation, and frequently a gross haptic test. Routinely that consists of asking patients to close their eyes and name a few common objects (coins, keys, cotton balls, etc) which are placed in their hands. Nevertheless, haptic abilities which are much more sophisticated play a crucial role in learning and development $t^{4.5}$ and have significant occupational consequences. Proficiency in various manual professional tasks is highly dependent on haptic perception, ranging from lifting boxes on a supermarket ${ }^{6}$ to performing exceedingly complex minimally invasive surgery?.

Nascimento et al. ${ }^{1}$ developed a tool which they called the Hand Haptic Perception Instrument (HHPI) and which is designed for an extensive evaluation of haptic perception, using widely available materials, in a standardized fashion. The article describes the process of development of the tool, which is yet to be tested in the field. Initially 5 therapists developed a draft of the tool, and subsequently submitted the tool to the evaluation of 30 experts who were carefully selected by strict criteria, including all having completed a $\mathrm{PhD}$ on health sciences. During this process experts suggested changes which were incorporated into the tool, and additional suggestions for further adaptations for different age groups and for patients with different pathologies. Due to the fact that haptic perception is dependent on various basic abilities like sensory perception (including touch and proprioception) and fine motor skills, patients with motor abnormalities might have difficulties with specific tasks in the scale. In addition, because part of the output consists on producing drawings, subjects with visual impairments or compromised motor skills might obtain lower scores in these specific tasks.

Acknowledging these limitations and the long way ahead until the tool is fully validated, the authors propose a neat and complete set of tests, which can be realistically applied. Furthermore, they provide an interesting and useful report on the development of the tool, which can be useful for other groups developing clinical scales. Given the fact that existing scales available in international literature are often expensive, and many times can not be applied to cross-cultural populations without great adaptations, the production of original scales suitable for local populations is a significant gap in our literature. In addition, given the limited availability of standardized tests for haptic perception, the current scale is contribution to the international literature, and further refinement and validation of this tool is likely to help thorough evaluation of this important and often overlooked skill. 
1. Nascimento LP, Martini J, Voos MC, Chien HF, Caromano A. Development of a new haptic perception instrument: a pilot study. Arq Neuropsiquiatr. 2015;74(1):75-80. doi:10.1590/0004-282X20150185

2. Henriques DYP, Soechting JF. Approaches to the study of haptic sensing. J Neurophysiol. 2005;93(6):3036-43. doi:10.1152/jn.00010.2005

3. Masson HL, Bulthé J, Op de Beeck HP, Wallraven C. Visual and haptic shape processing in the human brain: unisensory processing, multisensory convergence, and top-down influences. Cereb Cortex. 2015 Jul 28. doi:10.1093/cercor/bhv170
4. Lejeune F, Berne-Audéoud F, Marcus L, Debillon T, Gentaz E. The effect of postnatal age on the early tactile manual abilities of preterm infants. Early Hum Dev. 2014;90(5):259-64. doi:10.1016/j.earlhumdev.2014.02.002

5. Joanne Jao R, James TW, Harman James K. Multisensory convergence of visual and haptic object preference across development. Neuropsychologia. 2014;56:381-92. doi:10.1016/j. neuropsychologia.2014.02.009

6. Kingma I, Van Dieën JH, Toussaint HM. Scaling of lifting forces in relation to object size in whole body lifting. Ergonomics. 2005;48(8):1020-30. doi:10.1080/00140130500182197

7. Diana M, Marescaux J. Robotic surgery. Br J Surg. 2015;102(2):e15-28. doi:10.1002/bjs.9711 